\title{
4. PREPARATION OF WEAKLY CONSOLIDATED, LAMINATED HEMIPELAGIC SEDIMENT FOR HIGH-RESOLUTION VISUAL MICROANALYSIS: AN ANALYTICAL METHOD ${ }^{1}$
}

\author{
Kurt Andrew Grimm²
}

\begin{abstract}
A comprehensive method for preparation and analysis of weakly consolidated, laminated hemipelagic sediment for visual microanalysis is described. From a single $7-\mathrm{cm}^{3}$ sediment sample, subsamples for petrographic, backscattered electron, and secondary electron microscopy were prepared. The procedural steps described result in efficient sample preparation with minimal destructive alteration, permitting assessment of microfossil composition, detrital grain composition, microfossil taphonomy, and sedimentary fabric, at an exceptionally high degree of spatial and temporal resolution.
\end{abstract}

\section{INTRODUCTION}

Unlithified hemipelagic sediments-particularly laminated sediments deposited at high sedimentation rates - contain a paleoceanographic record that has been minimally altered by compaction and burial diagenesis. These discrete laminae may record short-term events in the water column that have important paleoclimatic significance (Grimm, this volume; Kemp, 1990; Anderson, et al., 1987).

Millimeter and submillimeter-scale laminae are commonly observed in anoxic marine sediments recovered by piston or box coring methods (Black Sea, Hay, 1988; Santa Barbara Basin, Soutar et al., 1981; Gulf of California, Baumgartner, et al., 1985). However, these and many other weakly consolidated and water-saturated sediments are difficult to prepare for visual microanalysis (Kemp, 1990; Swartz and Lindsay-Griffin, 1990; Jim, 1985). The method discussed herein permits a comprehensive visual analysis of sediments and sedimentary laminae from a single $7-\mathrm{cm}^{3}$ sediment sample using three different analytical modes (Pl. 1.1):

1. Petrographic thin-section reconnaissance of epoxy-impregnated sediment;

2. High-resolution imaging of sedimentary structures and grain types with the electron microscope in the backscattered electron mode (Pye and Krinsley, 1984; Krinsley and Manley, 1989; PI. 1.2), complemented with energy dispersive elemental microanalysis of discrete grains and laminae (Goldstein, et al., 1981; Pl. 1.3 and 2.1); these procedures are carried out on highly-polished and carbon-coated surfaces of epoxy-impregnated sediment blocks.

3. Detailed assessment of sediment fabric and microfossil composition with electron microscopy in the secondary electron mode; these observations are made upon sediment samples that are dehydrated in isopropyl alcohol and scrubbed ultrasonically in a bath of methanol before standard SEM preparation methods are employed (PI. 2.2 and 3.4).

Three major difficulties must be addressed when preparing soft sediment for detailed analysis. The first obstacle is the asymmetric volume loss associated with slow desiccation and the consequent destruction of delicate sedimentary fabrics (e.g., fine laminations) by cracking and sample disintegration. Second, the presence of specimen topography in sediment samples prepared and imaged with conventional SEM methods sharply limits the recognition of sedimentary laminae and grain types at the submillimeter to micrometer scale.

\footnotetext{
'Pisciotto, K. A., Ingle, J. C., Jr., von Breymann, M. T., Barron, J., et al., 1992. Proc. ODP, Sci. Results, 127/128 Pt. 1: College Station, TX (Ocean Drilling Program).

${ }^{2}$ Earth Sciences Board University of California Santa Cruz, CA 95064, U.S.A
}

Third, clay coatings upon grains commonly obscures sedimentary fabrics and prohibits precise faunal and floral assessment, thus limiting paleoceanographic interpretations. The analytical strategy we describe efficiently minimizes these prominent limitations.

\section{METHOD}

Seven $-\mathrm{cm}^{3}$ transparent plastic (polystyrene) cubes, commonly used aboard JOIDES Resolution for paleomagnetic sampling of soft sediment cores, are ideal for sampling. These cubes resemble a tiny, transparent cake box with a tight-fitting lid and are available from ASC Scientific (2075 Corte del Nogal, Suite 1, Carlsbad, CA 92009 , U.S.A.). Samples in this study were collected with the advanced piston core system during Leg 128 of the Ocean Drilling Program (Japan Sea; Ingle and Suyehiro, et al., 1990).

For sampling, label the bottom of the cube with a stratigraphic "up" arrow, remove the top, wet the cube in water, orient the wetted cube on the cut surface of the core and gently press the cube into the sediment; the vent hole on the bottom of the box allows air to escape, permitting easy penetration. After waiting several minutes, delicately remove the box from the core with the wetted blade of a lab spatula; two spatulas employed as forceps minimize disturbance of adjacent sediment. Once removed, place a $1-3-\mathrm{cm}^{3}$ shred of water-saturated spongy foam onto the exposed sediment surface (henceforth referred to as the top surface), replace the top, and carefully wrap the box with wax laboratory film. Then transfer the airtight sample box to a labeled plastic bag, and heat seal.

Carefully sealed samples may be kept for several months. Once ready for laboratory preparation, open the bag, remove the wax wrapping, and remove the top. Under a fume hood and using forceps, hold the sample upright and immerse it in a bath of crushed dry ice and isopropyl alcohol. The top surface should only be intermittently submerged; a gentle up-and-down motion seems to enhance vertical penetration into the specimen. We found best results with $90 \mathrm{~s}$ of immersion; however, ideal immersion time may vary in proportion to clay-content of the sediment.

After alcohol immersion, place the sample into a moderatevacuum chamber $\left(\sim 3 \times 10^{-3}\right.$ torr $)$ containing granular desiccant for $24 \mathrm{hr}$. Some minor shrinkage of the sample does commonly occur at this stage; however, the experiments indicate that the degree of shrinkage and cracking of treated specimens is significantly less than those in which no alcohol preparation was carried out. I attribute this observation to the fact that water is fully miscible in alcohol. I conjecture that alcohol replaces water in larger void spaces; as a consequence, interstitial clays and other grains are stripped of water and freed from the grasp of its high surface tension. In addition, alcohol is a volatile liquid and evaporates quickly, leaving the dried specimen intact and minimally altered. 
Once specimens have dried completely, remove them by running a thin, sharp blade around the inner margins of the cube, invert the sample, and dislodge the sediment cube with a gentle tap on the bottom. Then use a felt-tipped pen to mark stratigraphic "up" direction on the lower surface of the sample.

Proceed to cut the sediment cube in half (cut perpendicular to bedding laminations and perpendicular to the top surface) with a kerosene-lubricated lapidary saw, creating half I and half II. This delicate work is best done using a very narrow blade that rotates at high speed and lacks any wobble during rotation. After cutting, return half II specimens to original boxes, label, and store in a sealed jar with granular desiccant.

Half I samples may be transferred to $42-\mathrm{mL}$ foil weighing dishes for impregnation. Plastic sampling cubes should not be used because solvent in the resin interacts with polystyrene plastic, inhibiting polymerization of the epoxy. Furthermore, the ink of permanent marker pens is soluble in SPURR resin. Specimen labels may be taped to the shaft of a pin; placement of this flag along the stratigraphic upper margin of the specimen serves as an "up" indicator. Foil dishes can hold 4 to 5 labeled samples; these are then placed in a high vacuum $\left(\sim 10^{-5}\right.$ torr; evacuation of interstitial gases will enhance epoxy penetration; Jim, 1985).

We employed SPURR resin (available from Ernest F. Fullam, Inc., 900 Albany Shaker Road, Latham, NY 12110, U.S.A.) because of its very low viscosity, which permitted excellent sample penetration even in clay-rich sediments. Helpful suggestions on working with SPURR are found in Jim (1985) and Swartz and Lindsay Griffin (1990).

After mixing the four-component epoxy resin (we favor the "firm" recipe of Jim, 1985), the epoxy should be evacuated under a moderate vacuum $\left(3 \times 10^{-3}\right.$ torr $)$ for $10 \mathrm{~min}$. The epoxy will bubble and froth in its container, so use a sample container that exceeds epoxy volume by a factor of three or more to accommodate this turbulent process.

When the resin is ready, remove half I samples from high vacuum and place into the specimen boat with index tabs. Immerse the samples in epoxy, then return them to the moderate vacuum chamber $\left(3 \times 10^{-3}\right.$ torr) and left for $1 \mathrm{hr}$ at room temperature. This step permits thorough epoxy impregnation.

SPURR resin relies upon a thermal catalyst for polymerization to occur; following Jim (1985) we achieved optimal results by stepwise heating at $30^{\circ}, 40^{\circ}, 50^{\circ}$, and $60^{\circ} \mathrm{C}(24 \mathrm{hr}$ at each step $)$.

After curing, return to the kerosene-lubricated saw where the rigid epoxy chip is trimmed and cut in half; optimal results are achieved by bisecting the specimen parallel to the top surface, creating halves IA and IB. Standard methods may then be employed to make half IA into an ordinary petrographic thin section; Swartz and LindsayGriffin (1990) discussed problems with the use of automated thin-section equipment on epoxy impregnated samples. I employed water-free preparation to avoid inadvertent hydration of clay minerals.

After completing petrographic reconnaissance of half $1 \mathrm{~A}$ samples and selection of specimens for closer analysis, the surface of half IB was polished and prepared for electron microanalysis. Optimal image quality is favored by ultrahigh polish (Pye and Krinsley, 1984); excellent results were achieved by sequentially hand-polishing specimens on a sheet of glass, using a kerosene medium for $17 \mu \mathrm{m}$ and $9 \mu \mathrm{m}$ silicon carbide grit, followed by polishing steps with $5 \mu \mathrm{m}$ and $0.3 \mu \mathrm{m} \mathrm{Al}_{2} \mathrm{O}_{3}$ powder in ethyl alcohol.

Once the high polish has been achieved, half IB samples are mounted on conductive stubs, vacuum evacuated and carbon coated, in accordance with standard methods (Goldstein, et al., 1981).

High-resolution visual microanalysis of laminae is achieved by imaging of Half IIB with an electron microscope in the backscattered electron mode (BSEM; see Grimm, this vol.; Kemp, 1990). Unlike standard secondary electron microscopy (which relies upon differences in specimen topography for image resolution), BSEM records contrasts in mean atomic number and atomic density. As a consequence, contrasts in grain composition, grain shape, and sedimentary structure are immediately recognized against the black epoxy back- ground (Pl. 1.2). Resolution generally exceeds $10-20 \mathrm{~nm}$, approximately 15 times better than that achievable with visible light microscopy (Krinsley and Manley, 1989; Pye and Krinsley, 1984).

Many electron microscopes also possess an X-ray detector and associated energy dispersive analytical system (EDS; Goldstein, et al., 1981). EDS scans of individual grains permits recognition of constituent elements; consequently, composition of detrital and authigenic minerals may be accurately assessed. Furthermore, elemental dot-mapping permits recognition of fine-scale variability in bulk composition of discrete laminae (PI. 1.3 and 2.1). Employment of computer-based image analysis techniques upon elemental dot maps permits semiquantitative and graphical comparison of relative elemental abundances within sedimentary laminae (Grimm, unpubl. data).

Many details of microfossil structure are recognizable in BSEM images of epoxy-impregnated sediment blocks; however, the generic and specific identity of organisms is difficult to assess in cross-section. Consequently we prepared epoxy-impregnated foraminifer crosssections from hand-picked specimens of known identity. In this method, different foraminifer taxa were hand picked, transferred to plastic Beem capsules (available from Ted Pella, Inc., P.O. Box 2318, Redding, CA 96099 , U.S.A.) and impregnated with SPURR resin. Once the resin has cured, the samples are carefully polished on a rotating lapidary plate with $0.3 \mu \mathrm{m} \mathrm{Al} \mathrm{O}_{2} \mathrm{O}_{3}$ powder, yielding cross-sections through foraminifers whose generic and/or specific identity is known. These known foraminifer cross-sections are carbon coated and imaged in BSEM (PI. 2.33.3). Comparison of reference specimens to foraminifers occurring within sedimentary laminae permits confident identification of some foraminifer taxa in cross-section.

Once BSEM analyses have been completed, standard SEM imaging may be helpful for more precise assessment of microfossil composition and sediment fabric. At this stage, the base of half II is securely mounted on a conductive stub with standard epoxy. In the initial explorations I found that sedimentary and/or authigenic aggregates of clay minerals and organic matter commonly obscured grain microstructure. I report a satisfactory solution to this problem via immersion of the top surface of half II into an ultrasonic bath of methanol (Pl. 3.4). Do not immerse the entire specimen at this stage, for the entire sample may disintegrate. The stub provides a convenient handle for inversion and immersion of only the upper surface of the specimen. Good results were achieved with $30 \mathrm{~s}$ of immersion, however ideal duration may vary in proportion with clay-content and perhaps with clay mineralogy of the specimen. Visual inspection reveals detritus being removed by this process as it sloughs off and settles.

Following the ultrasonic cleaning step, the image surface of the specimen may be prepared for SEM imaging by conventional methods (Goldstein, et al., 1981).

\section{DISCUSSION}

The steps outlined above are diagrammed in Pl. 1.1; the numbered procedural steps permit efficient preparation, reconnaissance and data collection.

This simple method permits the satisfactory preparation of clayrich and diatomaceous hemipelagic sediments for high-resolution visual and elemental microanalysis. Using this method, I have successfully imaged submillimeter-scale laminations and dramatically improved achievable resolution of microfossil composition and taphonomy to the $1-100 \mu \mathrm{m}$ range (Grimm, this volume). Initial findings suggest that this method may be useful for other sediments that are clay-bearing and weakly-consolidated.

\section{ACKNOWLEDGMENTS}

Conversations with Rob Dunbar (Rice University) and Peggy Delaney (University of California, Santa Cruz) were helpful during initial explorations. The expertise of Eugenio Gonzalez, Jonathan Krupp, and Wilfred Bentham at UCSC is gratefully acknowledged, 
as is the capable assistance of Johanna Jurgens. Jim Ingle and Tara Kheradyar provided foraminifer samples. Helpful reviews were provided by Rick Behl, R. E. Garrison, and an anonymous reviewer. Samples were provided by Ocean Drilling Program. Research was supported by grant TAMU-20413.

\section{REFERENCES}

Anderson, R. Y., Hemphill-Haley, E., and Gardner, J. V., 1987. Persistent late Pleistocene-Holocene seasonal upwelling and varves off the coast of California. Quat. Res. N.Y., 28:307-313.

Baumgartner, T., Ferreira-Bartina, V., Schrader, H., and Soutar, A., 1985. A 20-year varve record of Siliceous phytoplankton variability in the Central Gulf of California. Mar. Geol., 64:113-129.

Goldstein, J. N., Newbury, D. E., Echlin, P., Joy, D. C., Fiori, C., and Lifshin, E., 1981. Scanning Electron Microscopy and X-Ray Microanalysis: New York (Plenum).

Hay, B. J., 1988. Sediment accumulation in the Central Western Black Sea over the past 5100 years. Paleoceanography, 30:491-508.

Ingle, J. C., Jr., Suyehiro, K., von Breymann, M. T., et al., 1990. Proc. ODP, Init. Repts., 128: College Station, TX (Ocean Drilling Program).

Jim, C. Y., 1985. Impregnation of moist and dry unconsolidated clay samples using Spurr resin for microstructural studies. J. Sediment. Petrol., 55:597-599.
Kemp, A.E.S., 1990. Sedimentary fabrics and variation in lamination style in Peru continental margin upwelling sediments. In Suess, E., von Huene, R., et al., Proc. ODP, Sci. Results, 112: College Station, TX (Ocean Drilling Program), 43-58.

Krinsley, D. H., and Manley, C. R., 1989. Backscattered electron microscopy as an advanced technique in petrography. J. Geol. Ed., 37:202-209.

Pye, K., and Krinsley, D. H., 1984. Petrographic examination of sedimentary rocks in the SEM using backscattered electron detectors. J. Sediment. Petrol., 54:877-888.

Soutar, A., Johnson, S. R., and Baumgartner, T. R., 1981. In search of modern depositional analogs to the Monterey Formation. In Garrison, R. E., et al. (Eds.), The Monterey Formation and Related Siliceous Rocks of California. Spec. Publ.-Soc. Econ. Mineral. Paleontol., Pacific Sect., 123-148.

Swartz, J. F., and Lindsay-Griffin, N., 1990. An improved impregnation technique for studying structure of unlithified cohesive sediments. In Suess, E., von Huene, R., et al., Proc. ODP, Sci. Results, 112: College Station, TX (Ocean Drilling Program), 87-91.

Date of initial receipt: 18 March 1991

Date of acceptance: 28 February 1992

Ms 127/128B-115 


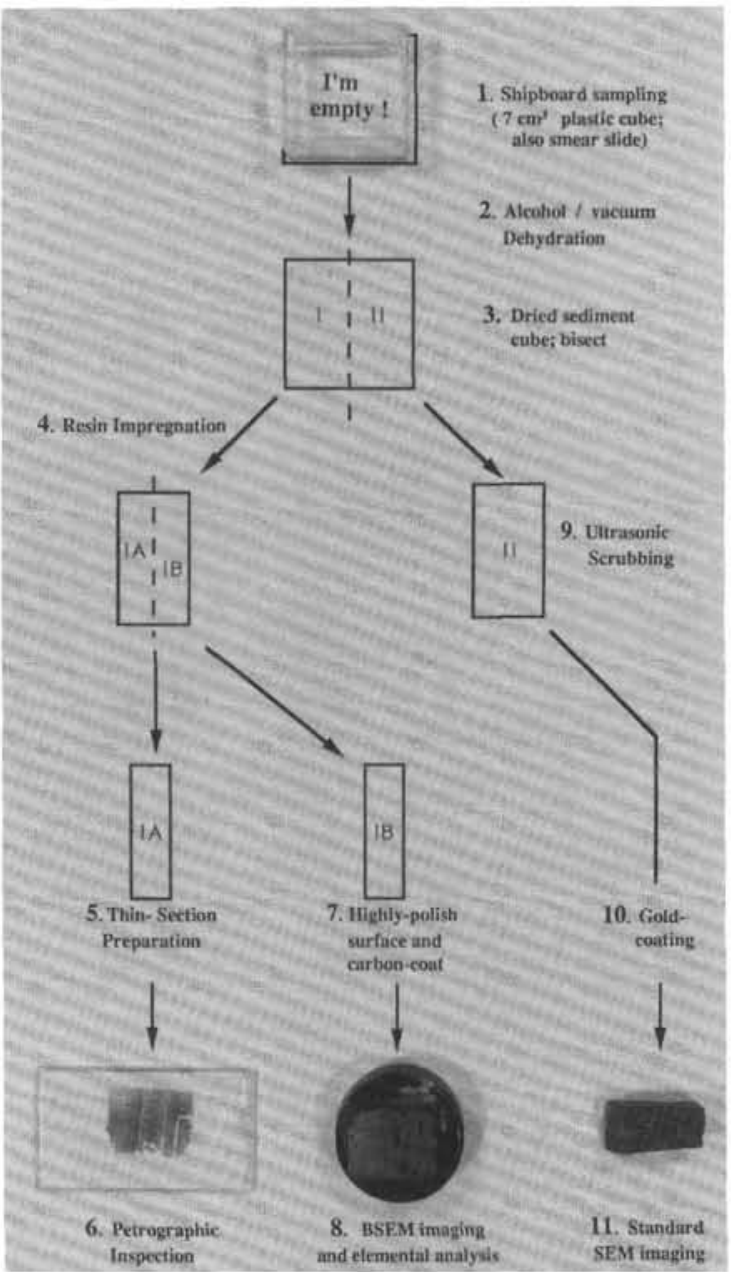

1

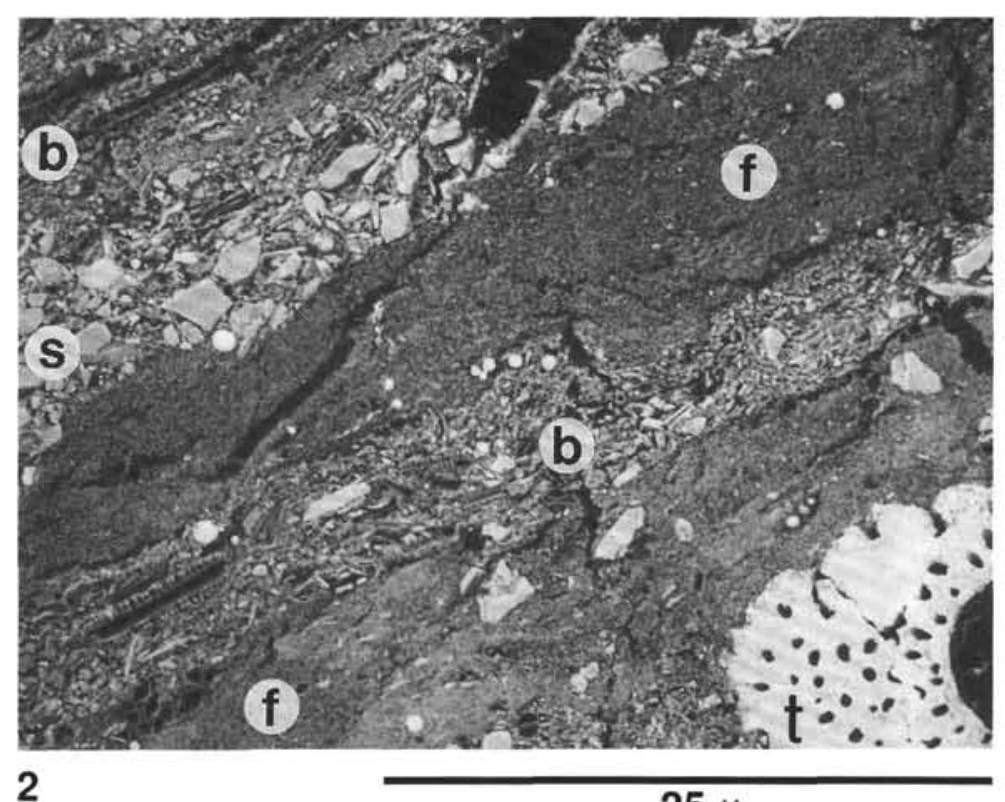

$25 \mu$

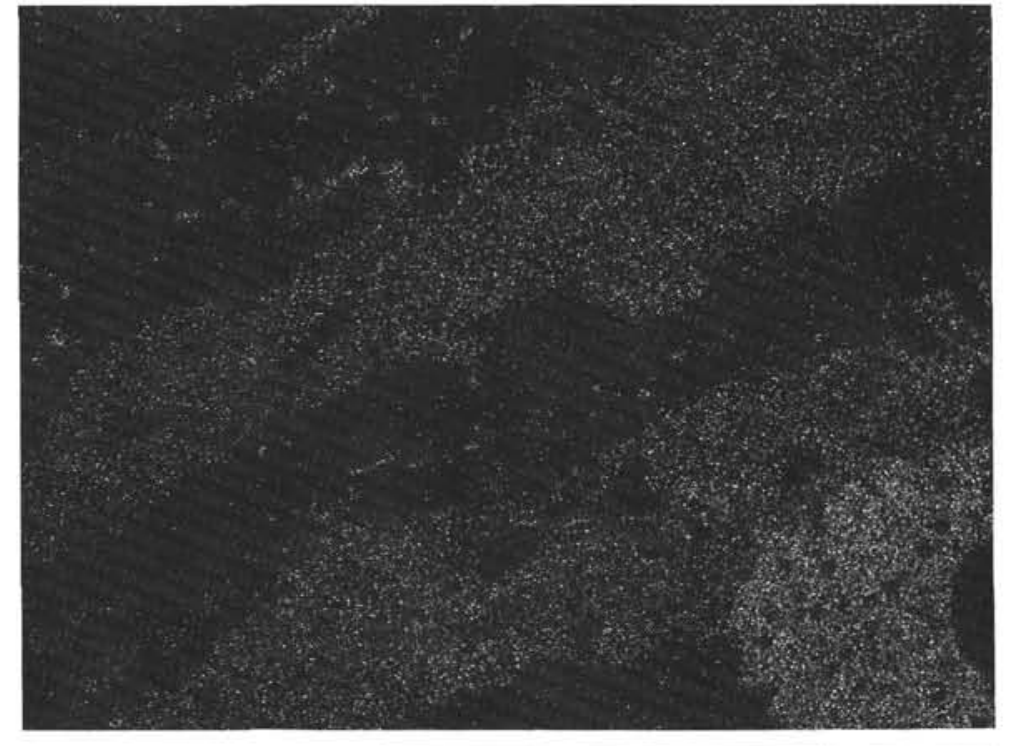

3

Plate 1. 1. Flowsheet of method, illustrating steps of sample preparation and analysis. At lower margin (left to right) are shown a petrographic thin section, an epoxy impregnated, carbon-coated sediment wafer for BSEM analysis and an ultrasonically scrubbed and Au-coated sediment chunk for standard SEM analysis. 2. BSEM photomicrograph. Note mixed biosiliceous laminae (b), detrital silt lamina

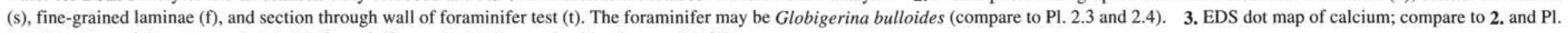
2.1. Note Ca-enrichment associated with foraminifers and with fine-grained lamina; see Pl. 2.2. 


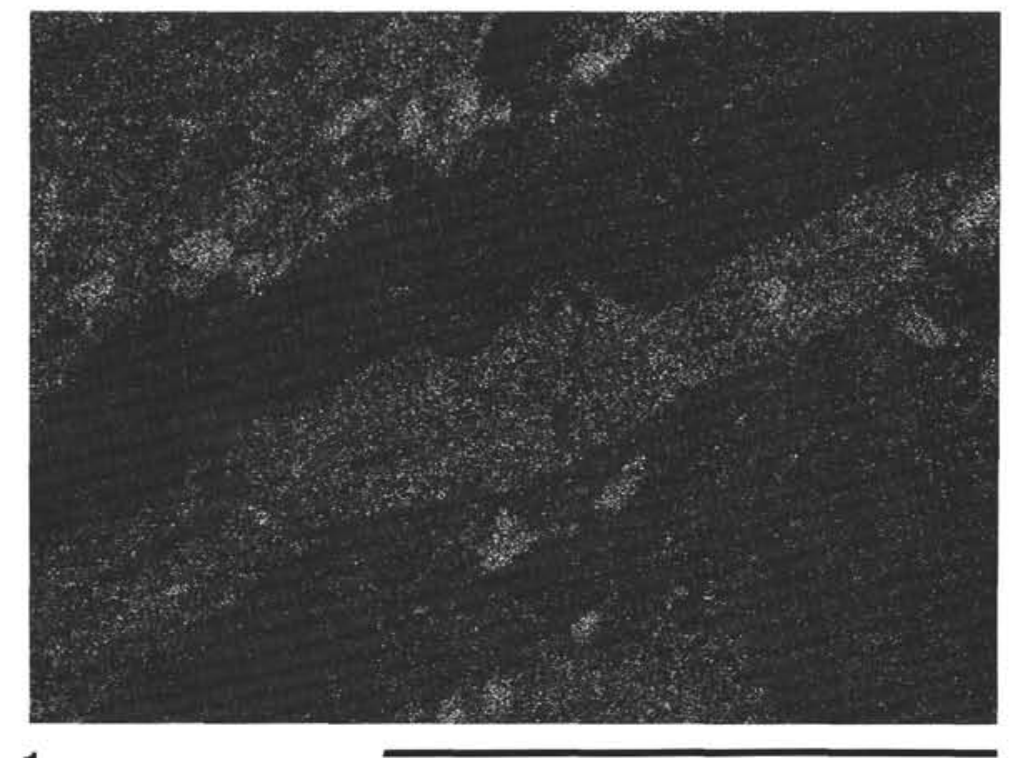

1

$25 \mu$
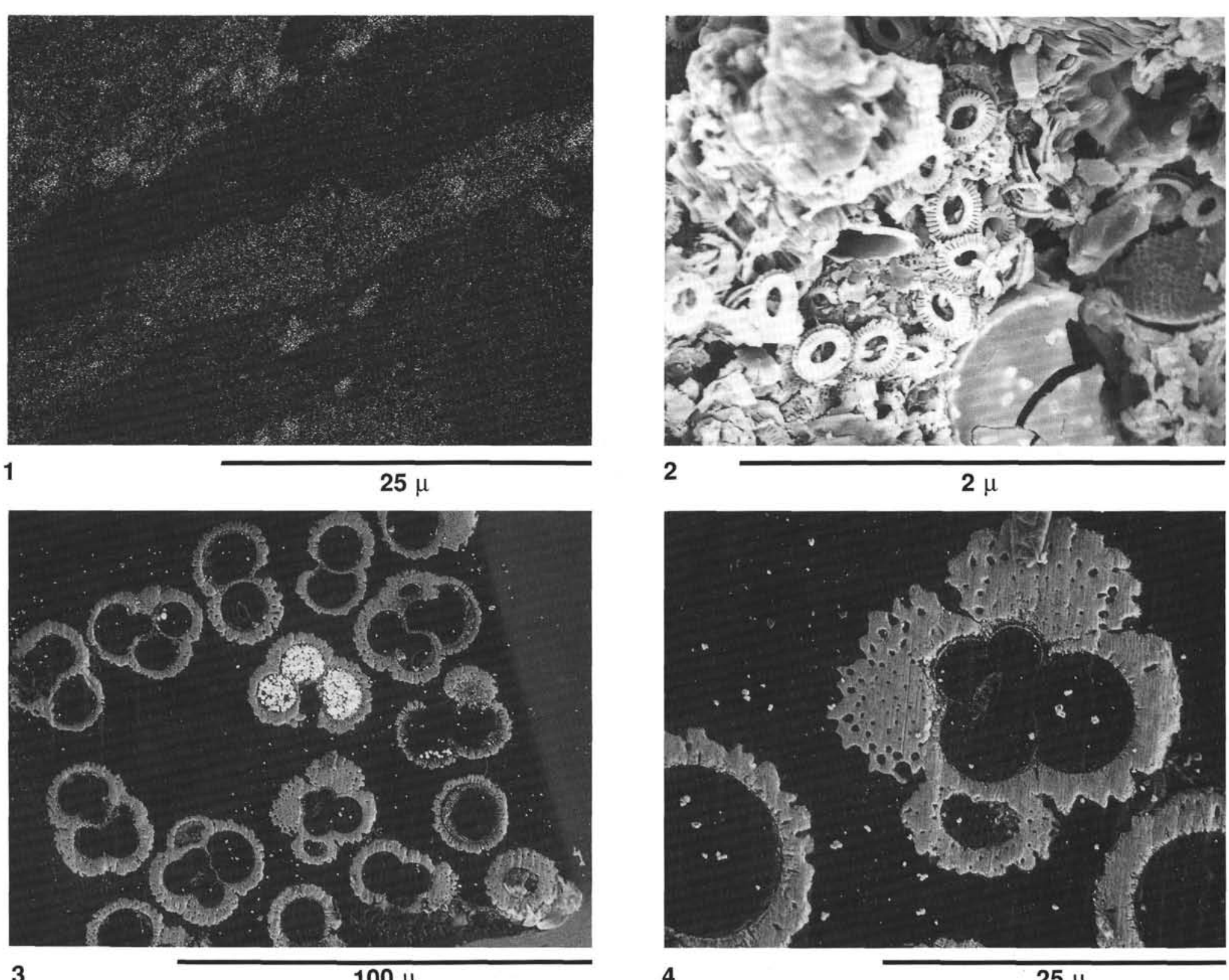

3

$100 \mu$

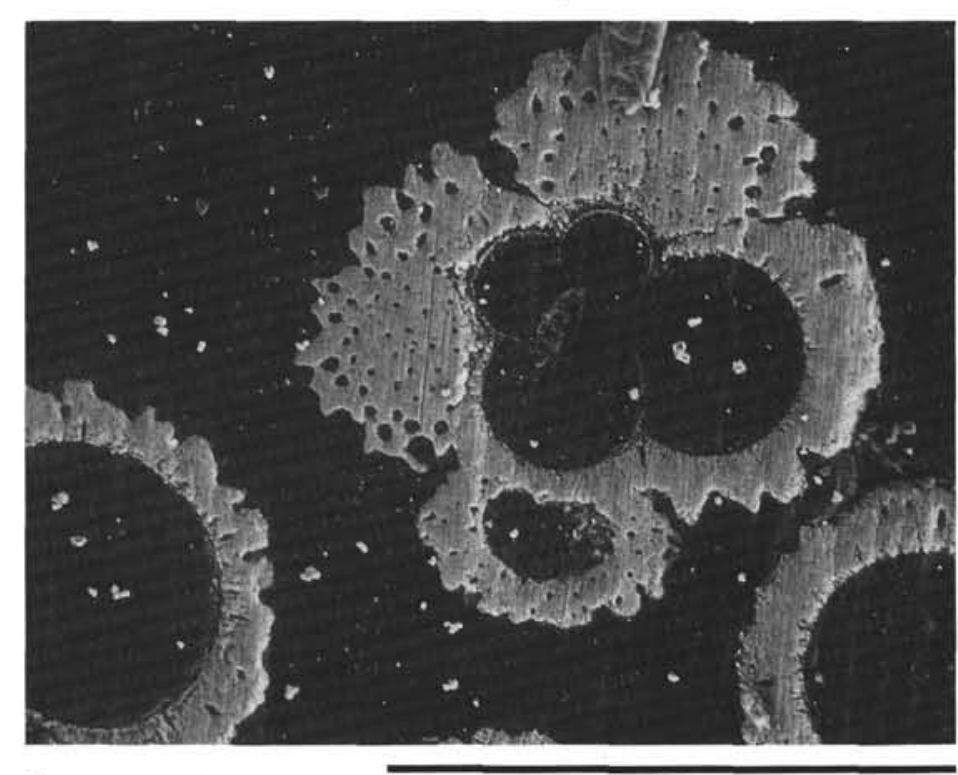

4

$25 \mu$

Plate 2. 1. EDS dot map of Si; compare to PI. 1.2 and 1.3. Note Si enrichment of biosiliceous and detrital silt laminae. 2. Secondary electron photomicrograph of sample illustrated in PI. 1.2, 1.3, and 2.1. Note calcareous nannofossils; their presence contributes to Ca-enrichment of some fine-grained laminae. 3. Foraminifer cross-section with BSEM; Globigerina bulloides. Test at center contains framboidal pyrite (bright white). Compare to PI. 2.4. 4. Foraminifer cross-section with BSEM; Globigerina bulloides. 

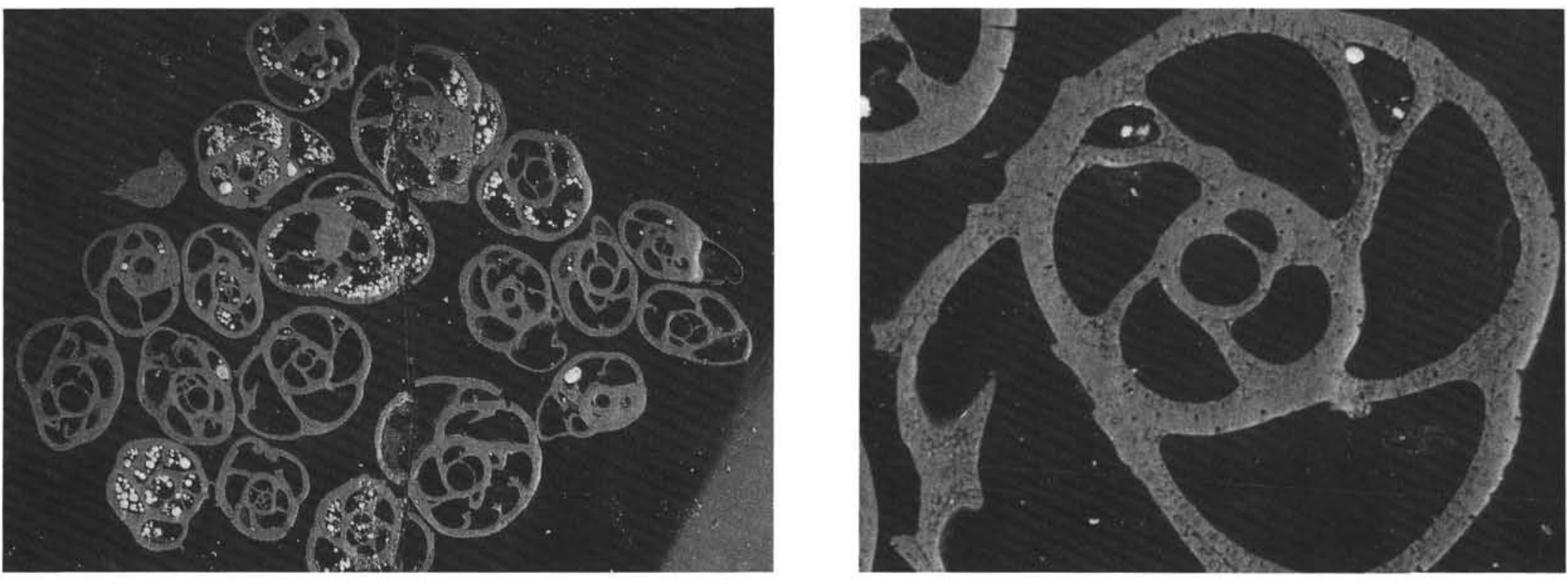

1

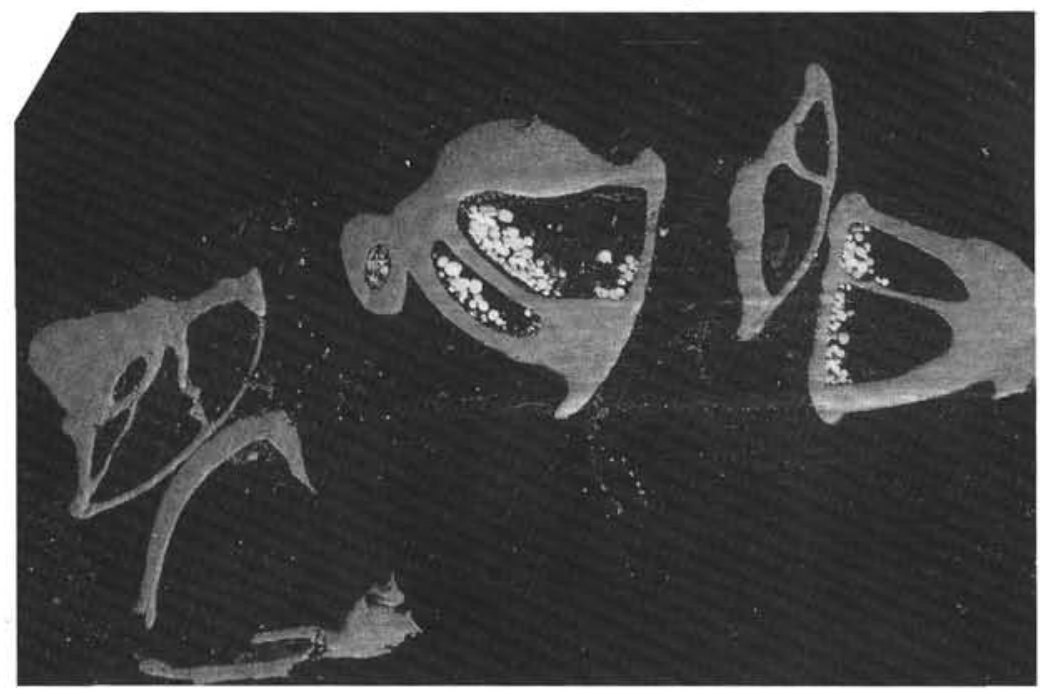

3

$100 \mu$
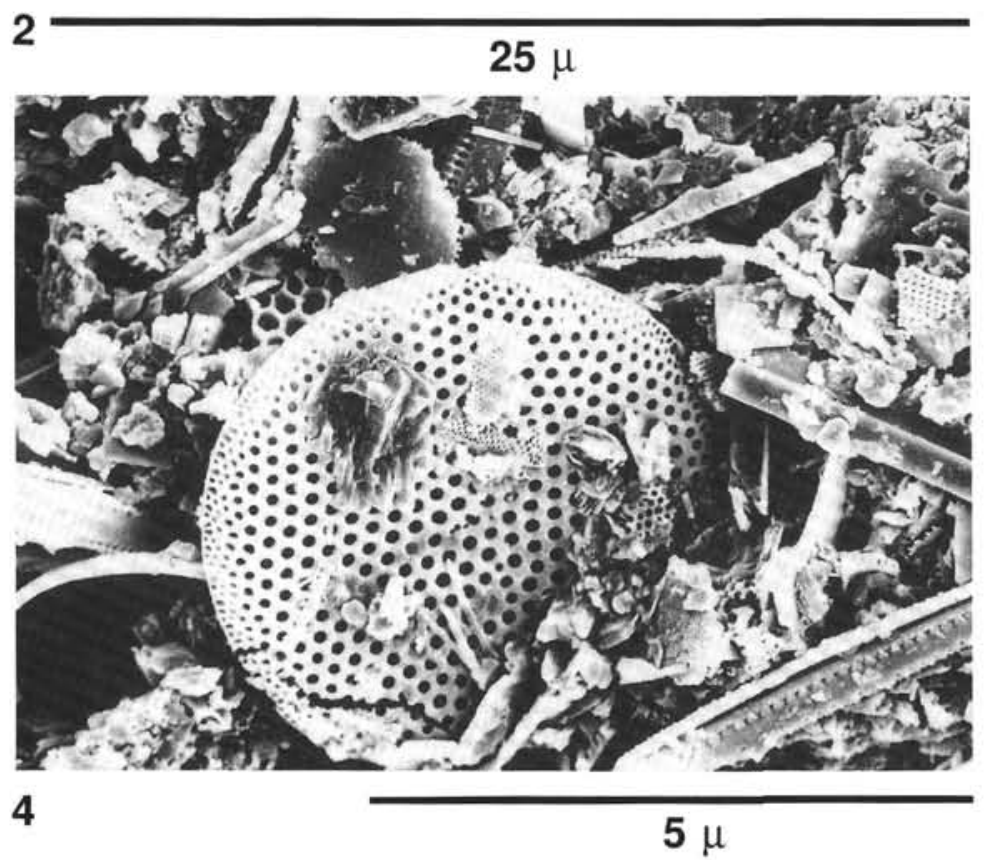

Plate 3. 1. Foraminifer cross-section with BSEM; Cassidulina. 2. Foraminifer cross-section with BSEM; Cassidulina. 3. Foraminifer cross-section with BSEM; Epistomonella. 4. Secondary electron photomicrograph of mixed biosiliceous debris. Detritus (clays) that commonly obscure microfossil detail has been removed from this sample by cleaning it in an ultrasonically agitated methanol bath. 